\title{
Isolamento de oligossacarídeos de xiloglucano de dicotiledôneas através de hidrólise enzimática e cromatografia de exclusão molecular
}

\author{
CLOVIS JOSÉ FERNANDES DE OLIVEIRA JUNIOR ${ }^{1}$, MARCIA REGINA BRAGA²e \\ MARCOS SILVEIRA BUCKERIDGE ${ }^{3,4}$
}

(recebido: 2 de fevereiro de 2006; aceito: 20 de julho de 2006)

\begin{abstract}
Isolation of xyloglucan oligossacharides from dicots using enzymatic hydrolyses and gel permeation chromatography). Oligosaccharides from xyloglucan, a plant cell wall polysaccharide, have been considered as signaling molecules capable of regulating cell growth and expansion. The purification of such oligosaccharides is an essential requirement to evaluate their biological activity. In the present work, xyloglucans extracted from seeds of copaiba (Copaifera langsdorffii Desf.) and bean cell suspension cultures (Phaseolus vulgaris L.) were hydrolyzed with cellulase (endo-glucanase) to obtain xyloglucan oligosaccharides (OXGs). The OXGs were separated by gel permeation chromatography and analysed by high performance anion exchange chromatography with pulse amperometric detector (HPAEC/PAD). The results indicate that these procedures were suitable for purification of OXGs since XLLG and XXXG were $90 \%$ and XXFG $80 \%$ pure, showing the expected biological activity.
\end{abstract}

Key words - cell wall, oligosaccharides, purification, xyloglucan

RESUMO - (Isolamento de oligossacarídeos de xiloglucano de dicotiledôneas através de hidrólise enzimática e cromatografia de exclusão molecular). Oligossacarídeos derivados do xiloglucano, um polissacarídeo constituinte da parede celular vegetal, vêm sendo considerados como moléculas capazes de sinalizar e/ou regular eventos relacionados ao crescimento e à expansão celular. A purificação desses oligossacarídeos é imprescindível para a realização de ensaios relativos à sua atividade biológica. Neste trabalho, xiloglucanos foram extraídos a partir de sementes de copaíba (Copaifera langsdorffii Desf.) e suspensões celulares de feijão (Phaseolus vulgaris L.) e hidrolisados com celulase (endo-glucanase) para obtenção dos oligossacarídeos de xiloglucano, os OXGs. Os resultados obtidos mostram que a técnica de cromatografia dupla em gel de exclusão molecular foi eficiente para purificação dos oligossacarídeos, apresentando OXGs dos tipos XLLG e XXXG com grau de pureza próximo a $90 \%$, e do tipo XXFG próximo de $80 \%$.

Palavras-chave - oligossacarídeos, parede celular, purificação, xiloglucano

\section{Introdução}

O xiloglucano é um polissacarídeo ramificado presente na parede celular dos vegetais superiores (Albersheim et al. 1996), sendo a hemicelulose predominante na parede primária de dicotiledôneas e monocotiledôneas não-gramíneas (Carpita \& Gibeaut 1993). Este polissacarídeo é formado por uma cadeia principal composta por glucoses ligadas $\beta, 1-4$ com ramificações laterais de xilose, xilose-galactose ou xilose-galactose-fucose, e apresenta a função estrutural e arquitetônica de conectar e espaçar as microfibrilas

1. Instituto de Botânica, Seção de Ornamentais, Caixa Postal 4005, 01061-970 São Paulo, SP, Brasil.

2. Instituto de Botânica, Seção de Bioquímica e Fisiologia de Plantas, Caixa Postal 4005, 01061-970 São Paulo, SP, Brasil.

3. Universidade de São Paulo, Departamento de Botânica, Rua do Matão, 277, Caixa Postal 11461, 05422-970 Cidade Universitária, Butantã, São Paulo, SP, Brasil.

4. Autor para correspondência: msbuck@usp.br de celulose (Hayashi 1989). O xiloglucano pode ser encontrado em sementes de muitas dicotiledôneas, nas quais pode ser acumulado como a principal fonte de reserva de carboidratos (Buckeridge \& Reid 1996). Os xiloglucanos são importantes como produtos biotecnológicos e, recentemente, foi demonstrado que aqueles obtidos a partir de sementes podem ser utilizados, por exemplo, para aumentar a qualidade do papel (Lima et al. 2004).

Quando hidrolisado com endoglucanases (figura 1), o xiloglucano é reduzido a blocos (oligossacarídeos de xiloglucano - OXGs) contendo quatro resíduos de glucose na cadeia principal, três resíduos de xilose ligados lateralmente às glucoses 1,2 e 3 , e estes resíduos de xilose podem ou não estar ramificados com resíduos de galactose ou galactose e fucose (Hayashi 1989). Fry et al. (1993) propuseram uma nomenclatura não ambígua para os oligossacarídeos de xiloglucano, na qual cada glucose da cadeia principal que não possui ramificação é denominada pela letra $\mathrm{G}$ e de acordo com o último monossacarídeo a ela ligado recebe uma letra 


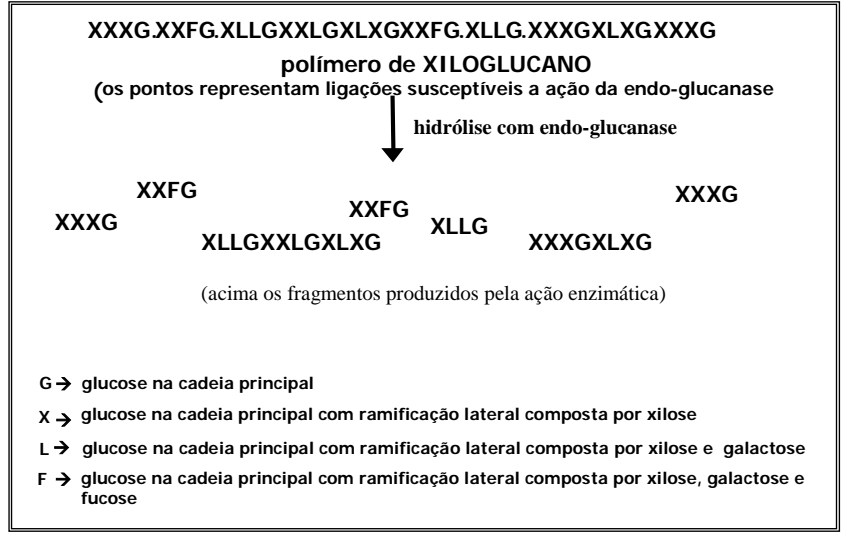

Figura 1. Esquema representando a hidrólise enzimática da molécula de xiloglucano com endo-glucanase e os oligossacarídeos gerados.

Figure 1. Scheme showing enzymatic hydrolysis of the xyloglucan molecule with endo-glucanase and the oligosaccharides generated.

diferente. Se o monossacarídeo ligado for a xilose, a unidade recebe a letra $\mathrm{X}$, ser for uma galactose uma letra $\mathrm{L}$, e caso exista um resíduo fucosil ligado à galactose, esta recebe uma letra $\mathrm{F}$.

Além das funções acima citadas, alguns estudos têm demonstrado que oligossacarídeos derivados do xiloglucano podem desempenhar funções regulatórias e/ou sinalizadoras na expansão e crescimento celular. Durante o metabolismo da parede celular ocorre a liberação de fragmentos deste polissacarídeo, os OXGs. Quando os OXGs contêm galactose em sua composição parecem atuar sinergisticamente às auxinas e quando apresentam fucose na sua estrutura, podem antagonizar o crescimento induzido por esses reguladores de crescimento (Fry 1986, McDougall \& Fry 1988, 1989a e b, Emmerling \& Seitz 1990, Lorences et al. 1990, Augur et al. 1992, Cutillas-Iturralde \& Lorences 1997, Vargas-Rechia et al. 1998, Oliveira Júnior et al. 2006).

Em sementes de copaíba (Copaifera langsdorffi Desf.), o xiloglucano é altamente galactosilado, sendo composto principalmente por XLLG, e em menores proporções, por outros tipos como XXXG, XXLG e XLXG, enquanto que em feijão (Phaseolus vulgaris L.) predominam XXXG e XXFG, com menores proporções dos tipos galactosilados.

No presente trabalho é descrita metodologia para obtenção de diferentes tipos de oligossacarídeos de xiloglucano, de forma que estes possam ser utilizados como padrões ou em experimentos relativos ao seu papel na sinalização e/ou regulação dos eventos relacionados à expansão e ao crescimento celular.

\section{Material e métodos}

Extração do xiloglucano de copaíba - Sementes de Copaifera langsdorffii Desf. foram coletadas de árvores cultivadas no Jardim Botânico do Instituto de Botânica de São Paulo e secas a $60{ }^{\circ} \mathrm{C}$ até peso constante e depois moídas. Ao pó resultante foi adicionada água destilada aquecida a $80{ }^{\circ} \mathrm{C}$ (100 mL g ${ }^{-1}$ de pó), com agitação continua durante 6 horas. Após a extração em água quente, o material foi filtrado em náilon tipo pele de ovo e ao filtrado foram adicionados 3 volumes de etanol para precipitação do xiloglucano. O precipitado foi mantido a $4{ }^{\circ} \mathrm{C}$ durante 16 horas. Após nova filtração para separação do xiloglucano, este foi lavado com etanol e acetona e depois seco em estufa a $50^{\circ} \mathrm{C}$. O material seco foi solubilizado em água destilada, centrifugado (para retirada de impurezas), congelado e liofilizado (Buckeridge et al. 1992).

Extração do xiloglucano de feijão - Sementes de feijão (Phaseolus vulgaris L. cv. Carioquinha) adquiridas no comércio local foram germinadas in vitro em meio MS (Murashige \& Skoog 1962), sem adição de reguladores de crescimento. Folhas e segmentos de caule foram utilizados para formação de calos e, a partir destes, foram iniciadas suspensões celulares, conforme descrito por Stella \& Braga (2002) para Rudgea jasminoides (Cham.) Müll. Arg. As suspensões foram filtradas em tela de náilon tipo pele de ovo, para separação das células e do meio extracelular (filtrado). As paredes das células foram extraídas de acordo com a metodologia de Karr \& Albersheim (1970), fracionadas segundo Gorshokova et al. (1996) e analisadas em sua composição de monossacarídeos através de cromatografia líquida de alta resolução com detecção por pulso amperométrico (HPAEC/PAD). A fração extraída com 4 M de KOH foi utilizada para obtenção do xiloglucano.

Hidrólise para obtenção dos oligossacarídeos de xiloglucano - Soluções dos xiloglucanos de copaíba e feijão $\left(1 \mathrm{mg} \mathrm{mL} \mathrm{mL}^{-1}\right)$ foram hidrolisadas separadamente com celulase (Megazyme $\left.{ }^{\circledR}\right)(20 \mu \mathrm{L}$ de celulase por $\mathrm{mL}$ da amostra), em tampão acetato de sódio $0,1 \mathrm{M}, \mathrm{pH}$ 5,0, e incubadas a $30^{\circ} \mathrm{C}$ por 48 horas. A hidrólise foi acompanhada a cada 12 horas por cromatografia de camada delgada (placa de sílica gel $60 \mathrm{~F}_{254}$ em alumínio - Merck) desenvolvida em solução de n-propanol: nitrometano: água (5/2/3 v/v/v) e revelada por aspersão com $\mathrm{H}_{2} \mathrm{SO}_{4} 5 \%$ em etanol, para verificação da hidrólise máxima do xiloglucano.

Análise dos oligossacarídeos de xiloglucano por cromatografia aniônica de alta resolução com detecção por pulso amperométrico (HPAEC/PAD) - Os oligossacarídeos de xiloglucano foram analisados em cromatografia líquida de alta resolução em sistema Dionex DX-500, utilizando coluna Carbo Pak PA100, eluída com um gradiente de acetato de sódio (35-70 mM em 50 minutos) e hidróxido de sódio $88 \mathrm{mM}$ constante, com fluxo de $0,9 \mathrm{~mL} \mathrm{~min}{ }^{-1}$. A identificação dos picos foi realizada conforme Tiné et al. (2000).

Cromatografia em gel de exclusão molecular - Os 
oligossacarídeos de xiloglucano resultantes da hidrólise com celulase foram cromatografados em coluna de exclusão molecular em BioGel P4 (com 2 cm de diâmetro e $150 \mathrm{~cm}$ de altura), eluída com água deionizada, sendo coletadas em frações de $2 \mathrm{~mL}$. Cada fração foi quantificada quanto aos teores de açúcares totais (segundo Dubois et al. 1956) e analisada por cromatografia líquida de alta resolução e detecção por pulso amperométrico (HPAEC/PAD), conforme descrito acima, para verificação da proporção dos diferentes tipos de oligossacarídeos de xiloglucano.

\section{Resultados e Discussão}

A extração do xiloglucano de copaíba resultou em rendimento de $46,7 \%$ do peso de pó seco da semente, contendo $0,4 \%$ de proteínas como contaminantes, não sendo detectada a presença de ácidos urônicos. Isso indica que o polissacarídeo obtido apresentou grau de pureza bastante elevado. Neste caso, foi obtido grau de pureza maior e também maior rendimento de xiloglucano a partir as sementes de copaíba, em comparação aos dados obtidos por Buckeridge et al. (1992).

No caso do xiloglucano de feijão, o rendimento foi de 12,6\% (fração $\mathrm{KOH} 4 \mathrm{M}$ ) em relação à matéria seca de parede celular extraída das células em suspensão e não foram detectados proteínas ou ácidos urônicos.

As proporções dos diferentes tipos de oligossacarídeos de xiloglucano (OXGs) obtidas após hidrólise com celulase e avaliadas por cromatografia líquida de alta resolução são apresentadas na figura 2. Os OXGs extraídos de copaíba são predominantemente galactosilados (XLLG), enquanto que os de feijão são principalmente dos tipos XXXG e XXFG. Esse resultado era esperado, uma vez que OXGs de copaíba foram extraídos a partir de sementes, sendo originários principalmente de paredes secundárias, que desempenham preferencialmente função de reserva, e para as quais têm sido descrita a presença de xiloglucanos não fucosilados (Buckeridge et al. 1992). Os OXGs de feijão, por sua vez, foram obtidos a partir de células cultivadas em suspensão, as quais são compostas quase que exclusivamente de paredes primárias, nas quais há alta proporção de xiloglucano fucosilado (Lima et al. 2004).

O perfil cromatográfico em gel de exclusão molecular dos oligossacarídeos de xiloglucano de copaíba é apresentado na figura 3A. Foram observados três picos distintos, sendo o pico F3 composto por OXGs contendo três blocos unidos (XXXGXXXGXXXG com

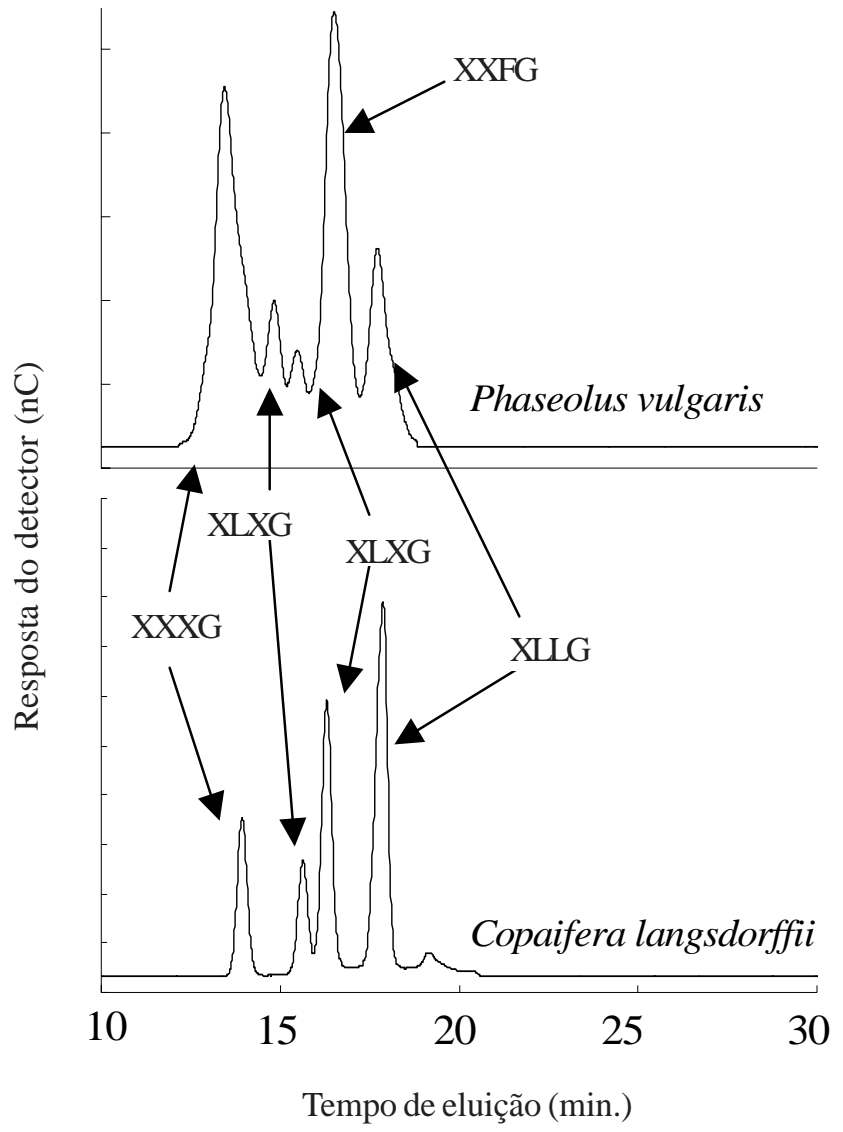

Figura 2. Perfis cromatográficos dos oligossacarídeos de xiloglucano extraídos de suspensões celulares de feijão (Phaseolus vulgaris L.) e de sementes de copaíba (Copaifera langsdorffii Desf.) obtidos por HPAEC/PAD.

Figure 2. Chromatographic profiles of xyloglucan oligosaccharides extracted from cell suspension cultures of common bean (Phaseolus vulgaris L.) and seeds of copaiba (Copaifera langsdorffii Desf.) obtained by HPAEC/PAD.

ramificações com galactose em diversas posições), totalizando 12 glucoses na cadeia principal; o pico F2 formado por OXGs com dois blocos (XXXGXXXG com ramificações com galactose em diversas posições) e o GR1 constituído de OXGs com apenas um bloco, com 4 glucoses na cadeia principal. Os oligossacarídeos de xiloglucano contendo um bloco são facilmente separados de F2 e F3, porém os diferentes tipos de OXGs dentro de F1 têm sua separação dificultada pela proximidade de seus pesos moleculares. Assim, com base na proporção relativa mostrada na figura $3 \mathrm{~B}$, apenas as frações com predominância de XLLG (51 a 55), foram reunidas. Este grupo, denominado GR1, foi analisado por HPAEC/PAD e o resultado é mostrado na figura 4A. Como o material ainda apresentava cerca de $30 \%$ de outros tipos de OXGs, foi então recromatografado em 
gel de exclusão molecular (BioGel P4) para obtenção de oligossacarídeos com um grau de pureza mais elevado (figuras 4B, C). As frações de números 51 a 55 foram reunidas por apresentarem alta proporção de XLLG, conforme observado na figura 4C, bem como boa quantidade de açúcares totais (figura 4B), e
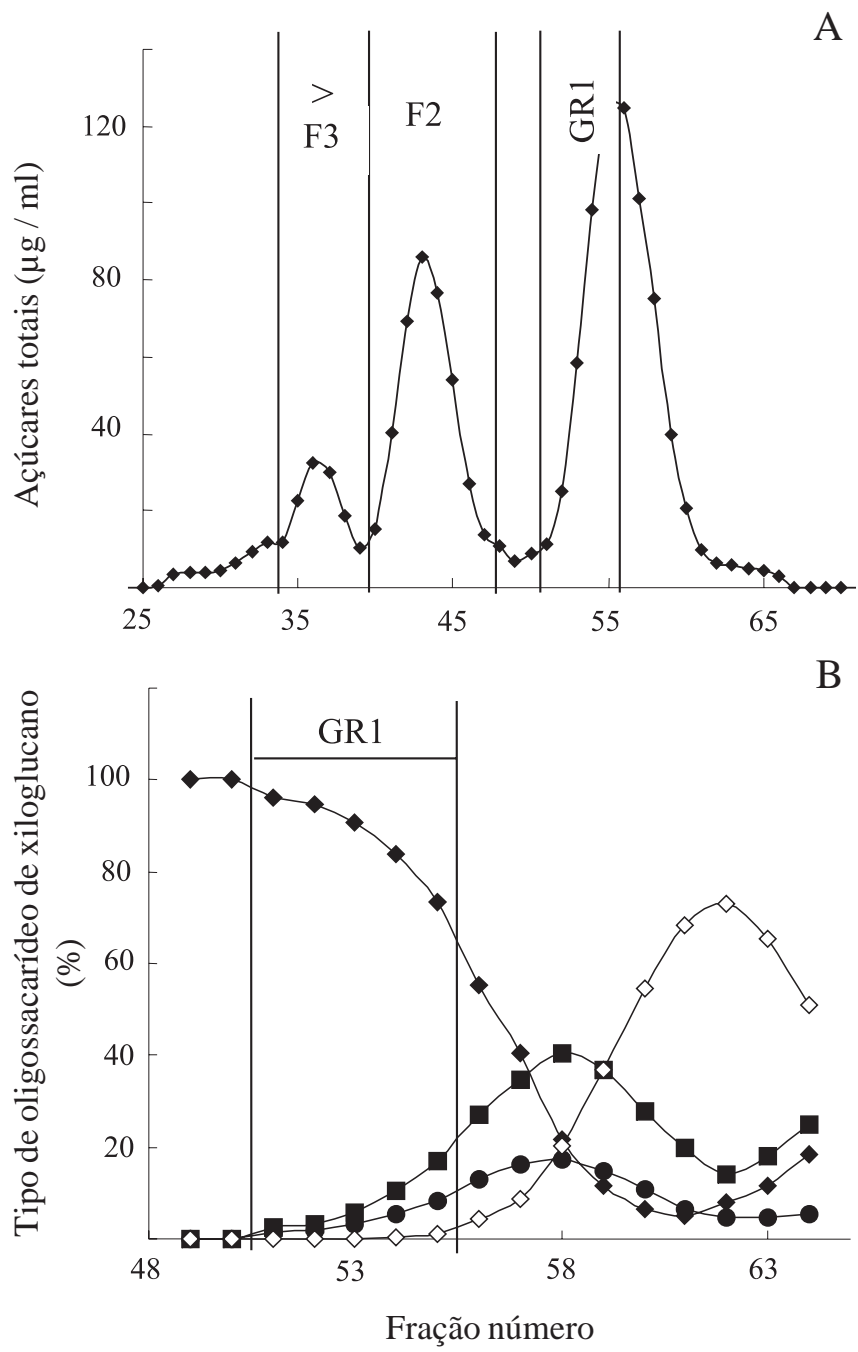

Figura 3. A. Perfil cromatográfico dos OXGs de Copaifera langsdorffii em coluna de BioGel P4. As faixas verticais representam o tipo de xiloglucano predominante (conforme análise apresentada em B). F3 e F2 representam blocos de OXGs com 3 e 2 unidades básicas de OXGs respectivamente; B. Porcentagem relativa dos OXGs nas frações provenientes da coluna de BioGel P4 e analisadas por HPAEC/PAD.

Figure 3. A. Chromatographic profile of the OXGs of Copaifera langsdorffii Desf. on a BioGel P4 column. The vertical stripes represent the type of xyloglucan that predominate (according to the analysis shown in B). F3 and F2 show blocks of OXGs with 3 and 2 basic units of OXGs respectively; B. Percentage of OXGs in the fractions obtained from the BioGel P4 column and analysed by HPAEC/PAD.

$\left(--_{-}=\mathrm{XLLG} ;-\boldsymbol{\square}_{-}=\mathrm{XXLG} ;-\bullet_{-}=\mathrm{XLXG} ;-\diamond_{-}=\mathrm{XXXG}\right)$.

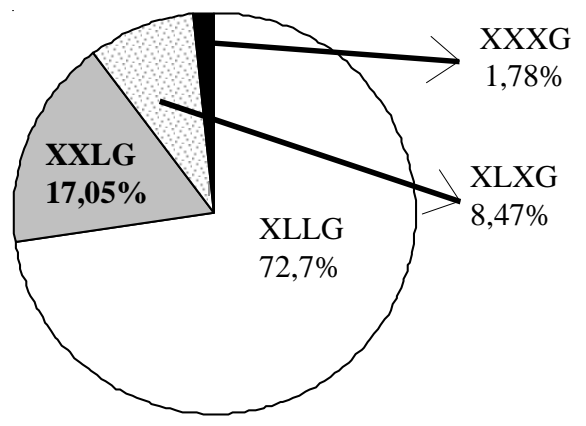

A

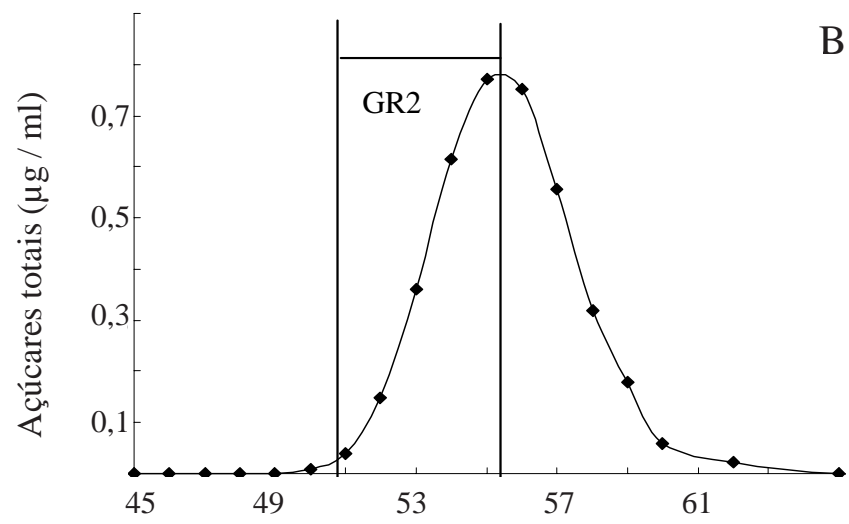

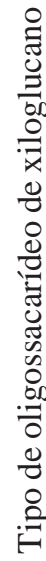

C

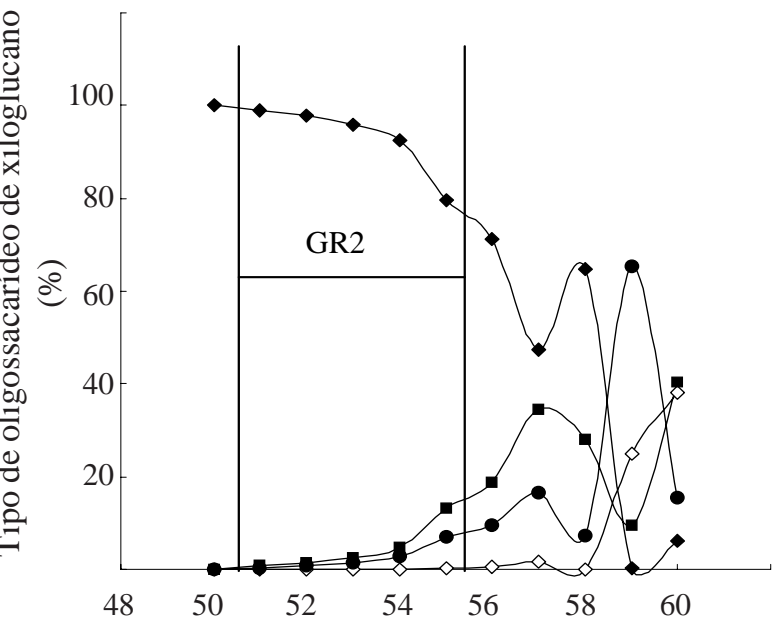

Fração número

Figura 4. A. Proporção dos oligossacarídeos de xiloglucano em GR1, analisada por HPAEC/PAD; B. Perfil cromatográfico de GR1 em BioGel P4; C. Porcentagem dos oligossacarídeos de xiloglucano nas frações recromatografadas de GR1, analisadas por HPAEC/PAD.

Figure 4. A. Proportion of xyloglucan oligosaccharides in GR1, analysed by HPAEC/PAD; B. Chromatographic profile of GR1in BioGel P4; C. Percentage of xyloglucan oligosaccharides in the fractions rechromatographed of GR1, analysed by HPAEC/PAD.

$\left(-\diamond_{-}=\mathrm{XXXG} ;-\bullet-=\mathrm{XLXG} ;-\boldsymbol{-}-=\mathrm{XLXG} ;-\bullet-=\mathrm{XXXG}\right)$. 
denominadas GR2. A análise de GR2 em HPAEC/PAD mostrou que este grupo apresentou cerca de $90 \%$ de XLLG (figura 5). O material foi considerado apropriado para utilização nos estudos sobre efeitos biológicos, pois além de apresentar pureza próxima de $90 \%$, os OXGs contaminantes também eram galactosilados (XXLG e XLXG). Em experimento sobre efeitos biológicos em suspensões celulares de Rudgea jasminoides (Cham.) Müll. Arg., o XLLG ocasionou diminuição do pH extracelular e aumento nas atividades de enzimas do metabolismo da parede celular (Oliveira Junior et al. 2006).

Para purificação de XXFG, o xiloglucano foi extraído a partir da parede de células de feijão cultivadas em suspensão. A porcentagem dos vários tipos de oligossacarídeos de xiloglucano encontrados na fração extraída com $4 \mathrm{M}$ de $\mathrm{KOH}$ é apresentada na figura 6 .

O perfil cromatográfico em coluna de BioGel P4, baseado nos teores de açúcares totais, é mostrado na figura 7A, e a proporção dos tipos de oligossacarídeos de xiloglucano em cada fração, analisada por HPAEC/PAD, encontra-se na figura 7B. Pela figura 7A podem-se observar 2 picos distintos, um formado por OXGs tipo F2, e outro por F1, no qual foram agrupadas as frações de 51 a 55 (GR3), que corresponderam àquelas com predominância de XXFG (figura 7B).

O grupo GR3 foi então recromatografado em BioGel P4. As frações 53 a 56 foram reunidas, formando o grupo GR4, por apresentarem alta proporção de XXFG e boa quantidade de açúcares totais, de acordo ao revelado pelas análises apresentadas nas figuras $8 \mathrm{~A}$ e $8 \mathrm{~B}$, respectivamente. Pode-se observar que a análise de GR4 por cromatografia líquida de alta resolução revelou a presença de cerca de $80 \%$ de XXFG

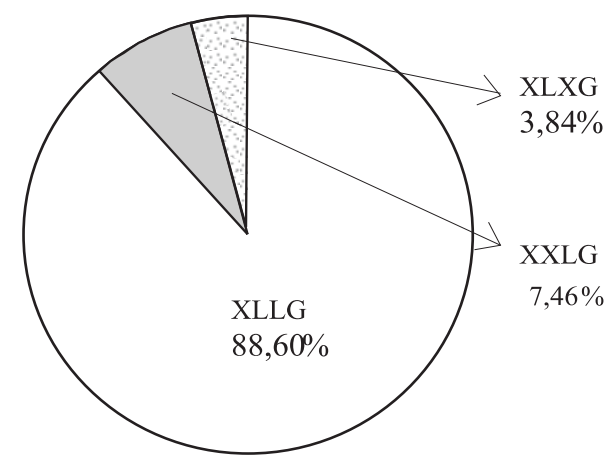

Figura 5. Proporção dos oligossacarídeos de xiloglucano em GR2, analisado por HPAEC/PAD.

Figure 5. Proportion of xyloglucan oligosaccharides in GR2 analysed by HPAEC/PAD.

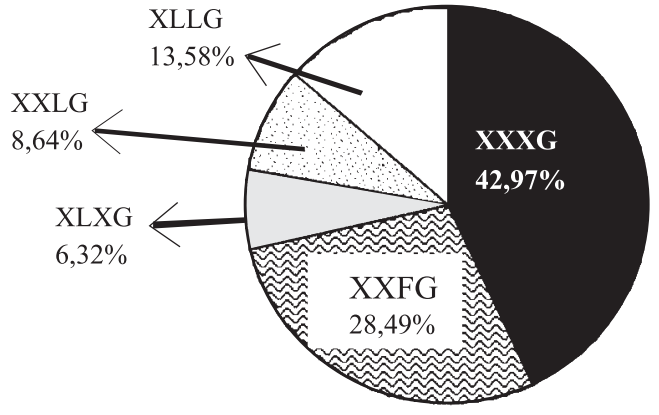

Figura 6. Proporção inicial dos oligossacarídeos de xiloglucano extraído da paredes de células de feijão cultivadas em suspensão, analisado por HPAEC/PAD.

Figure 6. Initial proportion of xyloglucan oligosaccharides extracted from walls of common bean cells cultivated in suspension, analysed by HPAEC/PAD.

(figura 9). Apesar da porcentagem ser inferior àquela obtida para os OXGs galactosilados de copaíba, uma nova purificação resultaria em redução no rendimento, que já foi considerado baixo, uma vez que apenas $28 \%$ do xiloglucano bruto de feijão eram constituídos de XXFG (figura 6). Além disso, o material foi considerado satisfatório para uso em experimentos sobre efeitos biológicos dos OXGs, tendo atividade biológica antagônica àquela mostrada pelos OXGs galactosilados extraídos de copaíba, quando ensaiado em suspensões celulares de $R$. jasminoides (Oliveira Junior et al. 2006).

OXGs do tipo XXXG também podem ser facilmente obtidos por este método. Conforme pode ser observado na figura 6, os OXGs extraídos da parede celular primária de feijão cultivado na forma de suspensão celular apresentaram cerca de $40 \%$ desse tipo de oligossacarídeo, e as frações da cromatografia em BioGel P4 coletadas no final do pico correspondente a F1 foram ricas em XXXG. Este tipo de OXG também foi purificado com grau de pureza acima de $90 \%$ (dados não mostrados).

Os dados apresentados indicam que a cromatografia dupla em gel de exclusão molecular (BioGel P4) em associação com análise das frações por cromatografia líquida de alta resolução (HPAEC/ PAD) pode ser considerada um procedimento eficiente para a obtenção de oligossacarídeos de xiloglucano, já que foi possível obter diferentes tipos de OXGs com elevado grau de pureza e que mostraram atividade biológica. Além disso, a metodologia utilizada apresentou excelente reprodutibilidade, o que permite sua utilização para a purificação de xiloglucanos de outras fontes. 
Em resumo, acredita-se que este procedimento possa ser utilizado para obtenção de preparações de oligossacarídeos a serem usadas como padrões ou em ensaios para avaliação de sua atividade biológica. Além disso, tais OXGS têm potencial biotecnológico (Urakawa et al. 2002), podendo ser aplicados futuramente e técnicas de nanotecnologia em setores como o farmacêutico, alimentício, de papel e de cosméticos.
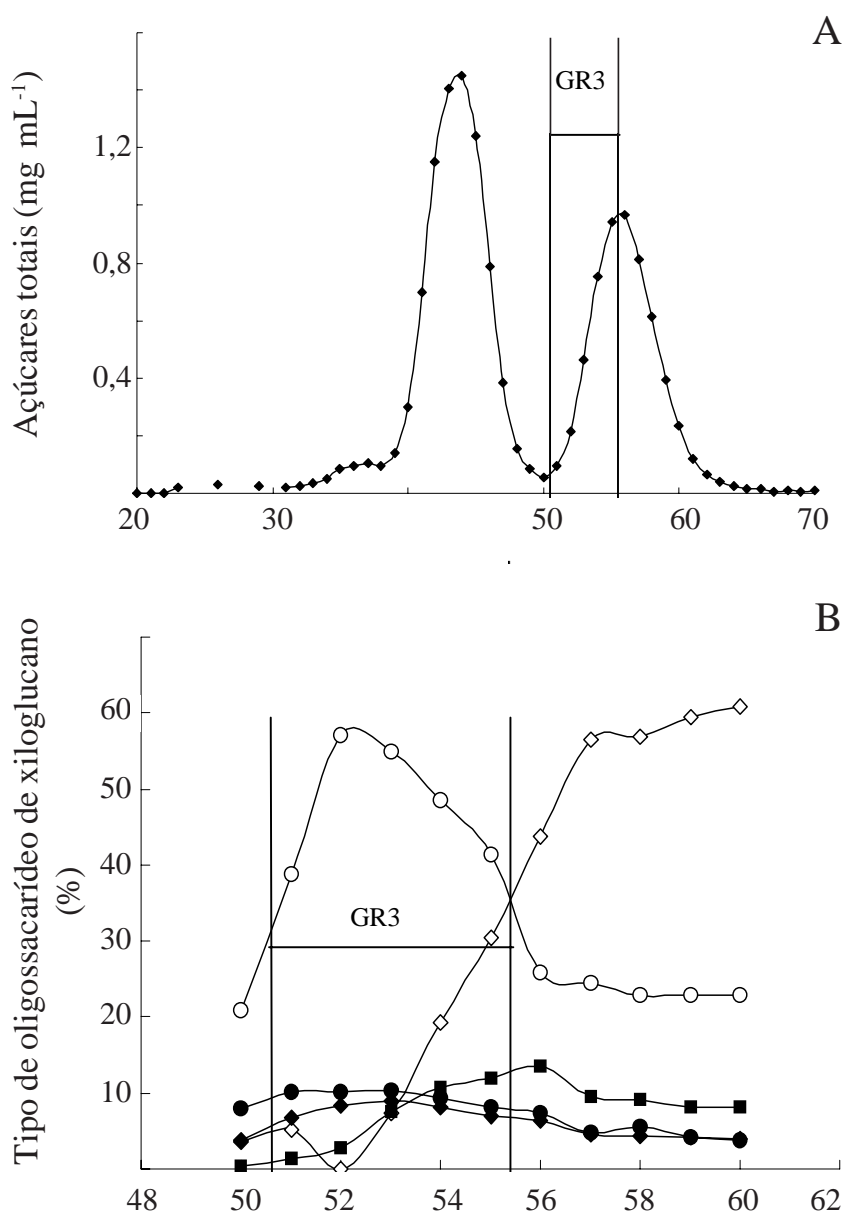

Fração número

Figura 7. A. Perfil cromatográfico dos oligossacarídeos de xiloglucano de feijão em BioGel P4, analisados pelos teores de açúcares totais; B. Porcentagem dos tipos de oligossacarídeos de xiloglucano de feijão nas frações coletadas na cromatografia em BioGel P4, analisadas por HPAEC/PAD.

Figure 7. A. Chromatographic profile of xyloglucan oligosaccharides from common bean in BioGel P4, analysed through their levels of sugars; B. Percentage distribution of different types of xyloglucan oligosaccharides of common bean in fractions collected after BioGel P4 chromatography, analysed by HPAEC/PAD.

$\left(-\diamond_{-}=\mathrm{XXXG} ;-\mathrm{O}_{-}=\mathrm{XXFG} ;-\bullet_{-}=\mathrm{XLXG} ;-\mathbf{-}-=\mathrm{XXLG}\right.$; $--=\mathrm{XLLG})$.

$B$
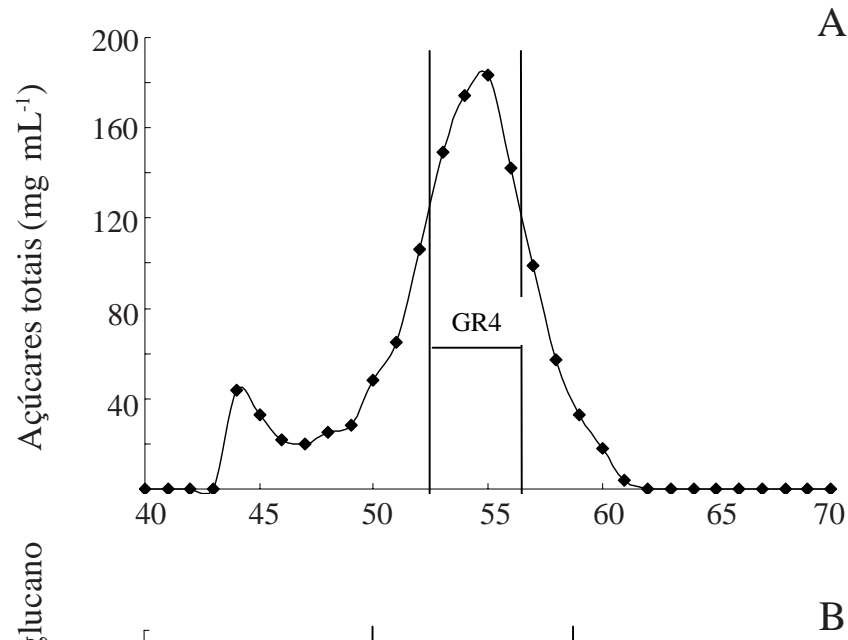

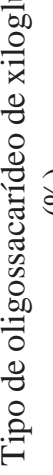

B

Figura 8. A. Perfil cromatográfico de GR3 em BioGel P4; B. porcentagem dos oligossacarídeos de xiloglucano nas frações recromatografadas de GR3, analisadas por HPAEC/PAD.

Figure 8. A. Chromatographic profile of GR3 in BioGel P4; B. Percentual distribution of xyloglucan oligosaccharide in rechromatographed fractions of GR3, analysed by HPAEC/PAD.
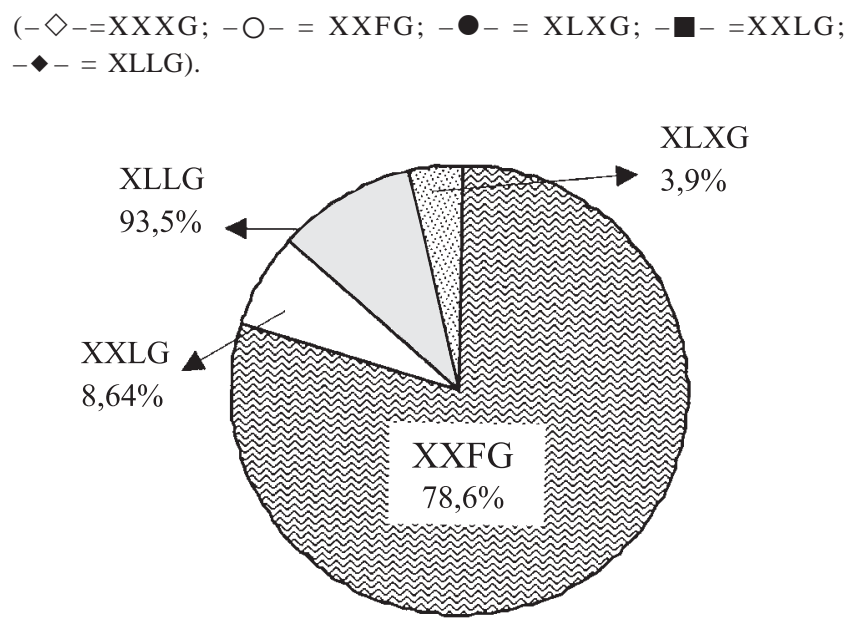

Figura 9. Proporção dos oligossacarídeos de xiloglucano em GR4, analisado por HPAEC/PAD.

Figure 9. Proportions of xyloglucan oligosaccharides in GR4, analysed by HPAEC/PAD. 
Agradecimentos - Os autores agradecem à Fapesp pelo financiamento do projeto temático dentro do programa Biota (processo 98.05124-8) e pela Bolsa de Doutoramento concedida a Clovis J. F. Oliveira Júnior (processo 99/04109-8). Marcos S. Buckeridge e Marcia R. Braga agradecem ao CNPq pelas Bolsas de Produtividade em Pesquisa.

\section{Referências bibliográficas}

ALBERSHEIM, P., DARVILL, A.G., O’NEILL, M.A., SCHOLS, H.A. \& VORAGEN, A.G.J. 1996. A hypothesis: The same six polysaccharides are components of the primary cell walls of all higher plants. In Pectins and Pectinases. (J. Visser \& A.G.J. Voragen, eds.). Elsevier Science. p.47-55.

AUGUR, C., YU, L., SAKAI, K., OGAWA, T., SINAŸ, P., DARVILL, A.G. \& ALBERSHEIM, P. 1992. Further studies of the ability of xyloglucan oligosaccharides to inhibit auxin- stimulated growth. Plant Physiology 99:180-185.

BUCKERIDGE, M.S. \& REID, J.S.G. 1996. Major cell wall storage polysaccharides in legume seeds: Structure, catabolism, and biological functions. Ciência e Cultura 48:153-162.

BUCKERIDGE, M.S., ROCHA, D.C., REID, J.S.G. \& DIETRICH, S.M.C. 1992. Xyloglucan structure and post-germinative metabolism in seeds of Copaifera langsdorfii from savanna and forest populations. Physiologia Plantarum. 86:145-151.

CARPITA, N.C. \& GIBEAUT, D.M. 1993. Structural models of primary cell walls in flowering plants: consistency of molecular structure with the physical properties of the cell wall during growth. The Plant Journal 3:1-30.

CUTILLAS-ITURRALDE, A. \& LORENCES, E.P. 1997. Effect of xyloglucan oligosaccharides on growth, viscoelastic properties, and long-term extension of pea shoots. Plant Physiology 113:103-109.

DUBOIS, M., GILLES, K.A., HAMILTON, J.K., REBELS, P.A. \& SMITH, F. 1956. Colorimetric methods for determination of sugars and telated substances. Analytical Chemistry 3:350-356.

EMMERLING, M. \& SEITZ, H.U. 1990. Influence of a specific xyloglucan-nonasaccharide derived from cell walls of suspension-culured cells of Daucus carota L. on regenerating carrot protoplasts. Planta 182:174-180.

FRY, S.C. 1986. In-vivo formation of xyloglucan nonasaccharide: a possible biologically active cell wall fragment. Planta 169:443-453.

FRY, S.C., YORK, W.S., ALBERSHEIM, P., DARVILL, A., HAYASHI, T., JOSELEAU, J.-P., KATO, Y., LORENCES, E.P., MACLACHLAN, G.A., MCNEIL, M., MORT, A.J., REID, J.S., SEITZ, H.U., SELVENDRAN, R.R., VORAGEN, A.G.J. \& WHITE, A.R. 1993. An unambiguous nomenclature for xyloglucan-derived oligosaccharides. Physiologia Plantarum 89:1-3.
GORSHOKOVA, T.A., WYATT, S.E., SALNIKOV, V.V., GIBEAUT, D.M., IBRAGIMOV, M.R., LOZOVAYA, V.V. \& CARPITA, N.C. 1996. Cell-wall polysaccharides of developing flax plants. Plant Physiology 110:721-729.

HAYASHI, T. 1989. Xyloglucans in the primary cell wall. Annual Review of Plant Physiology and Plant Molecular Biology 40:139-168.

KARR, A.L. \& ALBERSHEIM, P. 1970. Polysaccharidedegrading enzymes are unable to attack plant cell walls without prior action by a wall-modifying enzyme. Plant Physiology 46:69-80.

LIMA, D.U., LOH, W. \& BUCKERIDGE, M.S. 2004 Xyloglucan-cellulose interaction depends on the side chains and molecular weight of xyloglucan. Plant Physiology and Biochemistry 42:389-394.

LORENCES, E.P., MCDOUGALL, G.J. \& FRY, S.C. 1990. Xyloglucan and cello-oligosaccharides: antagonist of the growth promoting effect of $\mathrm{H}^{+}$. Physiologia Plantarum 80:109-113.

MCDOUGALL, G.J. \& FRY, S.C. 1988. Inhibition of auxinstimulated growth of pea stem segments by a specific nonasaccharide of xyloglucan. Planta 175:412-416.

MCDOUGALL, G.J. \& FRY, S.C. 1989a. Anti-auxin activity of xyloglucan oligosaccharides: the role of groups other than the terminal alfa-L-fucose residue. Journal of Experimental Botany 40: 233-238.

MCDOUGALL, G.J. \& FRY, S.C. 1989b. Structure activity relantioships for xyloglucan oligosaccharides with antiauxin activity. Plant Physiology 89:883-887.

MURASHIGE, T. \& SKOOG, F. 1962. A revised medium for rapid growth and bioassays with tobacco tissue culture. Physiologia Plantarum 15:473-497.

OLIVEIRAJUNIOR, C.J.F., BRAGA, M.R. \& BUCKERIDGE, M.S. 2006. Efeitos de oligossacarídeos de xiloglucano sobre o metabolismo extracelular de Rudgea jasminoides durante o crescimento. Hoehnea 33: 239-246.

STELLA, A. \& BRAGA, M.R. 2002. Callus and cell suspension cultures of Rudgea jasminoides, a tropical woody Rubiaceae. Plant Cell Tissue \& Organ Culture 68:271-276.

TINÉ, M.A.S., CORTELAZZO, A.L. \& BUCKERIDGE, M.S. 2000. Xyloglucan mobilisation in cotyledons of developing plantlets of Hymenaea courbaril L. (Leguminosae-Caesalpinoideae). Plant Science 154:117-126.

URAKAWA, H., MIMURA, M., \& KAJUWARA, K. 2002. Diversity and versatility of plant seed xyloglucan. Trends in Glycoscience and Glucotechnology 14: 355-376.

VARGAS-RECHIA, C., REICHER, F., SIERAKOWSKI, M.R., HEYRAUD, A., GRIGUEZ, H. \& LIÉNART, Y. 1998. Xyloglucan octasaccharide XXLGol derived from the seeds of Hymenaea courbaril acts as a signaling molecule. Plant Physiology 116:1013-1021. 